(2) Open Access Full Text Article

\title{
Investigation on dysfunctional beliefs and attitudes about sleep in Chinese college students
}

This article was published in the following Dove Press journal:

Neuropsychiatric Disease and Treatment

Lairun Jin'

Jun Zhou'

Hui Peng ${ }^{2}$

Shushu Ding'

Hui Yuan'

'School of Public Health, Wannan

Medical College, Wuhu, Anhui,

People's Republic of China;

${ }^{2}$ Department of Hospital Infection

Management, Yijishan Hospital of

Wannan Medical College, Wuhu,

Anhui, People's Republic of China
Correspondence: Hui Yuan School of Public Health, Wannan Medical College, No 22 Road Wenchangxi, Yijiang District, Wuhu, Anhui, 24I002, People's Republic of China

Tel +86 I39553629I2

Email yuanhui0553@I63.com
Objective: The aims of this study were to evaluate a subset of sleep-related cognitions and to examine whether dysfunctional beliefs and attitudes about sleep were associated with sleep quality in college students.

Patients and methods: A total of 1,333 college students were enrolled in this study by randomized cluster sampling. A brief version of Dysfunctional Beliefs and Attitudes about Sleep Scale (DBAS-16) was administered to college students at several colleges. Sleep quality was also assessed using the Pittsburgh Sleep Quality Index (PSQI). The DBAS-16 scores were analyzed across different demographic variables, corresponding subscales of 7-item PSQI, and relevant sleep behavior variables.

Results: A total of 343 participants were poor sleepers, while 990 were good sleepers, as defined by PSQI. The DBAS-16 scores were lower in poor sleepers than in good sleepers $(46.32 \pm 7.851$ vs $49.87 \pm 8.349, p<0.001)$, and DBAS-16 scores were lower in females and nonmedical students when compared with those in males and medical students, respectively (48.20 \pm 8.711 vs $49.73 \pm 7.923, p=0.001 ; 48.56 \pm 8.406$ vs $49.88 \pm 8.208, p=0.009$, respectively). The total score for sleep quality, as measured by PSQI, was negatively correlated with the DBAS-16 total score $(r=-0.197, p<0.01)$. There were significant differences in PSQI scores between individuals with attitudes and those without attitudes about sleep with respect to good sleep habits $(p<0.001)$, self-relaxation $(p=0.001)$, physical exercise $(p<0.001)$, taking sleeping pills $(p=0.004)$, and taking no action $(p<0.001)$.

Conclusion: Dysfunctional beliefs about sleep are associated with sleep quality and should be discouraged, especially for females and nonmedical college students.

Keywords: sleep, dysfunctional beliefs, college students, sleep quality, cognition

\section{Introduction}

Poor sleep is considered as an inability to get a full length or good quality of sleep or a frequent feeling of not been refreshed the next morning, leading to daytime impairments such as reduced energy and sleep anxiety. ${ }^{1}$ As a public health problem, poor sleep has continued to receive increasing attention. Approximately $30 \%$ of insomnia patients suffer from irritability, distraction, memory difficulties, fatigue, anxiety and depression, and attention defect. Insufficient motivation or low moods can result in reduced efficiency in personal learning and performance. ${ }^{2}$ Sleep disturbance is a catalyst for the development of problems of substance abuse. ${ }^{3}$ Evaluation and surveillance of sleep health help to reduce manifestations concerning sleep disturbance, such as vehicular traffic accidents related to drowsiness. ${ }^{4}$ These developments arise because of a large corpus of evidence showing that poor sleep quality is related to elevated morbidity. ${ }^{5}$ Data from epidemiological and laboratory studies show that insufficient sleep results in weight gain and obesity, ${ }^{6}$ stroke, ${ }^{7}$ depression, ${ }^{8}$ and other unhealthy outcomes. 
Some researchers presented a cognitive model of sleep disturbance, suggesting that subjects with poor sleep are usually overly anxious about their sleep duration. This kind of thinking activity triggers both autonomic awakening and emotional distress. ${ }^{9}$ Insomnia symptoms are significantly improved after intervention in beliefs about sleep in patients with poor sleep..$^{10}$ Dysfunctional beliefs about sleep are excessive and negatively toned cognitive activities about getting enough sleep and about the impact the sleep disturbance is having on health and/or daytime functioning. For example, such beliefs about sleep-promoting behaviors may lead to unscientific behaviors, and beliefs about consequences of insomnia can cause excessive negative thinking about daytime performance. Beliefs by individuals about the unpredictability of sleep can cause fear of losing control of sleep. Such faulty appraisal may turn normal changes in sleep patterns into clinical problems or prolong normal sleeplessness into chronic problems. Perception of sleep deficits is regarded as a likely persistent predisposition to recurrences of depression and emotional distress. However, some researchers found that the extent of depression does not exactly match the level of dysfunctional beliefs about sleep in patients with both sleep disorders and anxiety. Cognitive interventions for depression may not alter erroneous beliefs about sleep. ${ }^{11}$ If such beliefs are found in those with sleep disturbance, adjuvant therapy may be effective. Consequently, cognitive activity about sleep is considered as a special and deserving research goal. Many results demonstrate that distorted beliefs and perceptions may be important psychological factors for determination of sleep quality and suggest that beliefs play significant roles by not only translating into relevant behaviors but also affecting actual physiological responses to emotions. ${ }^{12-15}$

Excessive attention to sleep may deteriorate sleep disorders, which in turn may result in excessive cognitive activity. ${ }^{9}$ It has been reported that subjects with erroneous beliefs about sleep are convinced that their lives will be affected if they do not get enough sleep. ${ }^{16,17}$ Studies found that $37 \%$ of primary school students suffer from sleep-related problems, including bedtime resistance. ${ }^{18}$ In the clinics, sleep quality is assessed by the self-reported measure of the Pittsburgh Sleep Quality Index (PSQI) scale. Sleep disorder is defined by the PSQI total score $\geq 7$. Dysfunctional cognition about sleep is associated with temporary sleep disturbance, and the improvement in cognitive activity about sleep helps to relieve poor sleep. ${ }^{19}$ Despite the fact that researchers are increasingly becoming aware of the important role of cognitive factors in insomnia, there are little based on a rather big sample and a new combination of variables among college students. Most college students have their own mobile phones, which they consider indispensable in their lives..$^{20} \mathrm{It}$ has been reported that prolonged usage of electrical devices (including personal mobile phones, computers, tablets, and game consoles) increases the risk of insomnia. ${ }^{21,22}$ In college students, the relationship between sleep and overall health cannot be ignored, especially the development of important psychosomatic functions such as behavior, subjective life satisfaction, emotion, and attentiveness. ${ }^{23,24}$ Given the importance of good sleep to college students ${ }^{25}$ and in view of the fact that many students complain about difficulty in falling asleep, ${ }^{26}$ this study was conducted to unravel useful data for improving sleep by evaluating a subset of beliefs about sleep in college students. This was with a view to finding out whether erroneous beliefs about sleep were related to sleep disturbance in Chinese college students.

\section{Patients and methods}

\section{Participants}

The subjects in this study were recruited from four colleges in Anhui, People's Republic of China. They were selected by randomized cluster sampling and asked to fill out the study questionnaire. They were drawn from different majors and grades of each selected college or university. The exclusion criteria used in this study included individuals who submitted ineligible questionnaire or blank questionnaire, those who filled out the questionnaire wrongly, and those with inaccurate or incomplete demographic information needed for data analysis.

\section{Measurements}

\section{Dysfunctional Beliefs and Attitudes about Sleep Scale (DBAS-16)}

The DBAS-16 was developed to determine the type of individual beliefs and attitudes about sleep, and it was initially designed by Morin et al. ${ }^{27}$ The original 30-item scale was shortened to a 16-item scale of beliefs about sleep including "I need to catch up on sleep loss" and "Insomnia can destroy life". ${ }^{28}$ The DBAS-16 has been validated in both short and long forms for use across different insomnia patient groups..$^{28,29}$ This scale is progressively being used in academic research and clinical diagnostics around the world, and it has been translated into several languages including Chinese. . $8,30-32^{2}$ The 16-item version of the scale has adequate test-retest reliability $(r=0.928)$ and internal consistency (Cronbach's alpha values range from 0.786 to 0.835$).{ }^{33}$ The Chinese version of the DBAS-16 has a higher reliability and validity than other 
tested versions, and it is a more suitable version for assessing maladaptive cognition in the Chinese population. It contains not only well-differentiated clinical items but also items that are more sensitive to cognitive behavioral therapy (CBT). Therefore, the DBAS-16 was administered to evaluate beliefs and attitudes about sleep in this study. The scoring range for each item was from 1 (at the "strongly disagree" pole) to 5 (at the "strongly agree" pole). The DBAS-16 score is the sum of scores of all 16 items ranging from 16 to 80 . The scale has four derived themes or subscales: 1) consequences of insomnia (items 5, 7, 9, 12, and 16); 2) worry/helplessness about sleep (items 3, 4, 8, 10, 11, and 14); 3) expectations for sleep (items 1 and 2); and 4) medication (items 6, 13, and 15). The more erroneous beliefs a participant have, the lower his or her total score.

\section{PSQI}

The PSQI is a self-reported measure that reflects the subjects' sleep quality during the past few months based on 19 items and five additional questions. The last five questions are not calculated in the scoring, because these questions are evaluated by a bedmate. The PSQI has been validated for reliability and efficacy in the diagnosis of narcolepsy syndrome. It can specifically distinguish "good sleepers" from "poor sleepers". ${ }^{44}$ The Chinese version of the PSQI is also a valid and reliable scale for investigating and screening sleep quality, and it was used to evaluate participants' sleep quality in the present study. ${ }^{35,36}$ The 19 items in the PSQI are divided into seven subcomponents: subjective sleep quality (item 6), sleep latency (items 2 and 5a), sleep duration (item 4), habitual sleep efficiency (items 1, 3, and 4), sleep disturbance (items $5 \mathrm{~b}-5 \mathrm{j}$ ), use of sleep medication (item 7) and daytime dysfunction (item 8 and 9). The scores for each of these components can range from 0 to 3 . Usually, the scores are summed up to create a total score ranging from 0 to 21 . Poor sleepers have PSQI total score $\geq 7$, while good sleepers have PSQI scores $<7$. Thus, a high PSQI indicates a poorer sleep quality.

\section{General demographic information}

The questionnaire contained items associated with demographic variables, including age, gender (males/females), grade, major, self-assessment of personality, and types of colleges and universities (medical college and nonmedical college). As part of the requirements of the current study, participants were also asked about daily measures taken by them to improve sleep quality, such as improving the sleep environment, developing good sleep habits, self-relaxation, consulting a doctor, strengthening physical exercise, taking sleeping pills, reading, as well as taking no action at all.

\section{Statistical analyses}

SPSS 18.0 software was used for analysis of all data. Means and standard deviations were used to describe data. Analysis of variance (ANOVA) and Student's $t$-test were conducted for comparing means. The Student-Newman-Keuls (SNK) was used for post hoc analyses. The SNK is a multiple range test with a statistic of $q$. Pearson's correlations were then used to examine the relationships between dysfunctional cognition and sleep quality. A two-tailed $p$-value $<0.05$ was taken to be statistically significant.

\section{Ethics}

All participants were informed of the research intent, and they signed informed consent form. For participants younger than 18 years, their parental written informed consent was obtained. This study was approved by the ethics committee of Wannan Medical College.

\section{Results Sample characteristics}

A total of 1,500 questionnaires were distributed, while 1,333 effective questionnaires were collected $(88.87 \%$ effectiveness). The participants $(\mathrm{N}=1,333$, mean age $=$ $20.74 \pm 1.31$ years, $49 \%$ females) were categorized into 343 poor sleepers and 990 good sleepers according to their PSQI scores. The group of good sleepers had a mean age of $20.72 \pm 1.28$ years, while the poor sleepers had a mean age of $20.82 \pm 1.36$ years. There were 397 medical students and 936 nonmedical college students; $30.31 \%$ of the subjects were freshman, 33.08\% were sophomore students, $34.81 \%$ were junior students, while the rest were senior students. The demographic information of the participants and their DBAS-16 scores are shown in Table 1. Subjects ranged in age from 16 to 26 years, with a mean age of 20.74 years. Participants had a mean DBAS-16 score of $48.95 \pm 8.366$.

Table I Ages of the subjects and their scores on the DBAS-16 (mean $\pm \mathrm{SD}, \mathrm{N}=1,333$ )

\begin{tabular}{lllll}
\hline Characteristics & Minimum & Maximum & Mean & SD \\
\hline Age (years) & 16 & 26 & 20.74 & I.3I \\
Consequences of insomnia & 5 & 25 & 14.58 & 3.313 \\
Worry/helplessness about sleep & 6 & 30 & 18.52 & 3.750 \\
Expectations for sleep & 2 & 10 & 4.56 & 1.615 \\
Medication & 3 & 15 & 11.29 & 2.411 \\
Total DBAS-16 & 16 & 80 & 48.95 & 8.366 \\
\hline
\end{tabular}

Abbreviation: DBAS-16, Dysfunctional Beliefs and Attitudes about Sleep Scale. 


\section{DBAS-16 scores of the sample}

As shown in Table 2, the DBAS-16 total score did not show significant difference with respect to some demographic variables such as grade, age, self-evaluation of character, and type of college. There were significant differences between males and females in DBAS-16 total score $(t=3.352$, $p=0.001)$, DBAS-16 worry/helplessness subscale score $(t=3.208, p=0.001)$, and DBAS-16 medication subscale score $(t=7.405, p<0.001)$. Grade ANOVA demonstrated a significant difference in DBAS-16 medication subscale score $(F=5.057, p=0.002)$. ANOVA analysis of age also showed a significant difference in DBAS-16 medication subscale score $(F=4.428, p=0.012)$. Medical students had better beliefs about sleep $(t=2.627, p=0.009)$ than nonmedical students. Moreover, poor sleepers, defined by PSQI $\geq 7$, had significant decreases in DBAS-16 total and subscale scores when compared with good sleepers (DBAS-16 total score: $t=6.874, p<0.001$; DBAS-16 consequences subscale score: $t=4.894, p<0.001$; DBAS-16 worry/helplessness subscale score: $t=8.174, p<0.001$; and DBAS-16 medication subscale score: $t=3.457, p=0.001$ ). These results are shown in Table 2.

\section{Correlation between subscales of the PSQI and the DBAS- 16 subscales}

Results of Pearson's correlation analysis of total and subscale scores of DBAS-16 and PSQI are shown in Table 3. There were zero-order correlations among the continuous variables

Table 2 DBAS-16 total and subscale scores in the different groups

\begin{tabular}{|c|c|c|c|c|c|c|}
\hline Variables & $\mathbf{n}$ & $\begin{array}{l}\text { Consequences } \\
\text { of insomnia }\end{array}$ & $\begin{array}{l}\text { Worry/helplessness } \\
\text { about sleep }\end{array}$ & $\begin{array}{l}\text { Expectations } \\
\text { for sleep }\end{array}$ & Medication & $\begin{array}{l}\text { Total } \\
\text { DBAS-16 }\end{array}$ \\
\hline \multicolumn{7}{|l|}{ Gender } \\
\hline Male & 679 & $|4.53 \pm 3.33|$ & $18.86 \pm 3.610$ & $4.57 \pm 1.601$ & $11.78 \pm 2.077$ & $49.73 \pm 7.923$ \\
\hline Female & 654 & $14.62 \pm 3.298$ & $18.20 \pm 3.855$ & $4.56 \pm 1.630$ & $10.82 \pm 2.610$ & $48.20 \pm 8.711$ \\
\hline$t$ & & 0.476 & 3.208 & 0.036 & 7.405 & 3.352 \\
\hline$p$-value & & 0.634 & 0.001 & 0.972 & $<\mathbf{0 . 0 0 1}$ & 0.001 \\
\hline \multicolumn{7}{|l|}{ Grade } \\
\hline Freshman & 404 & $14.70 \pm 3.372$ & $18.65 \pm 3.748$ & $4.61 \pm 1.604$ & $11.57 \pm 2.254^{\mathrm{a}}$ & $49.52 \pm 8.319$ \\
\hline Sophomore & 441 & $14.60 \pm 3.240$ & $18.55 \pm 3.672$ & $4.61 \pm 1.655$ & $11.39 \pm 2.407^{a}$ & $49.14 \pm 8.264$ \\
\hline Junior & 464 & $14.43 \pm 3.356$ & $18.35 \pm 3.778$ & $4.50 \pm 1.58 \mid$ & $10.95 \pm 2.5 \mathrm{I} \mathrm{I}^{\mathrm{a}}$ & $48.24 \pm 8.474$ \\
\hline Senior & 24 & $15.04 \pm 2.742$ & $19.38 \pm 4.6 \mid 4$ & $4.21 \pm 1.744$ & $11.33 \pm 2.444^{a}$ & $49.96 \pm 8.416$ \\
\hline$F$ & & 0.643 & 0.902 & 0.799 & 5.057 & 1.937 \\
\hline$p$-value & & 0.587 & 0.440 & 0.494 & 0.002 & 0.122 \\
\hline \multicolumn{7}{|l|}{ Age (years) } \\
\hline $16-19$ & 211 & $14.69 \pm 3.356$ & $18.57 \pm 3.807$ & $4.55 \pm 1.496$ & $11.73 \pm 2.202^{\mathrm{a}}$ & $49.53 \pm 8.279$ \\
\hline $20-22$ & $\mathrm{I}, 027$ & $|4.5| \pm 3.350$ & $|8.56 \pm 3.72|$ & $4.58 \pm 1.646$ & $11.23 \pm 2.455^{\mathrm{a}}$ & $48.88 \pm 8.452$ \\
\hline $23-26$ & 95 & $14.95 \pm 2.765$ & $|8.0| \pm 3.945$ & $4.48 \pm 1.584$ & $11.02 \pm 2.288^{a}$ & $48.46 \pm 7.621$ \\
\hline$F$ & & 0.908 & 0.960 & 0.151 & 4.428 & 0.702 \\
\hline$p$-value & & 0.403 & 0.383 & 0.860 & 0.012 & 0.496 \\
\hline \multicolumn{7}{|c|}{ Self-evaluation of character } \\
\hline Extrovert & 219 & $|4.8| \pm 3.768$ & $18.64 \pm 4.073$ & $4.49 \pm 1.601$ & $11.23 \pm 2,647$ & $49.17 \pm 9.430$ \\
\hline Partial extrovert & 566 & $14.61 \pm 3.324$ & $18.47 \pm 3.925$ & $4.52 \pm 1.596$ & $11.28 \pm 2.510$ & $48.88 \pm 8.677$ \\
\hline Partial introvert & 494 & $|4.50 \pm 3.04|$ & $18.56 \pm 3.389$ & $4.69 \pm 1.654$ & $|1.34 \pm 2.15|$ & $49.10 \pm 7.388$ \\
\hline Introvert & 54 & $13.98 \pm 3.606$ & $18.28 \pm 3.759$ & $4.15 \pm 1.433$ & $11.17 \pm 2.648$ & $47.57 \pm 8.965$ \\
\hline$F$ & & 1.031 & 0.201 & 2.577 & 0.162 & 0.602 \\
\hline$p$-value & & 0.378 & 0.896 & 0.052 & 0.922 & 0.614 \\
\hline \multicolumn{7}{|l|}{ Type of college } \\
\hline Medical college & 397 & $14.82 \pm 3.304$ & $18.82 \pm 3.639$ & $4.66 \pm 1.678$ & $11.58 \pm 2.235$ & $49.88 \pm 8.208$ \\
\hline Nonmedical college & 936 & $|4.47 \pm 3.3| 3$ & $|8.40 \pm 3.79|$ & $4.52 \pm 1.587$ & $11.17 \pm 2.472$ & $48.56 \pm 8.406$ \\
\hline$t$ & & 1.742 & 1.904 & 1.374 & 2.951 & 2.627 \\
\hline$p$-value & & 0.082 & 0.057 & 0.170 & 0.003 & 0.009 \\
\hline \multicolumn{7}{|l|}{ PSQI } \\
\hline$<7$ & 990 & $14.84 \pm 3.292$ & $19.01 \pm 3.655$ & $4.59 \pm 1.635$ & $1 \mathrm{I} .43 \pm 2.349$ & $49.87 \pm 8.349$ \\
\hline$\geq 7$ & 343 & $13.83 \pm 3.265$ & $17.13 \pm 3.677$ & $4.48 \pm 1.556$ & $10.89 \pm 2.542$ & $46.32 \pm 7.851$ \\
\hline$t$ & & 4.894 & 8.174 & 1.183 & 3.457 & 6.874 \\
\hline$P$-value & & $<0.001$ & $<0.00 \mathrm{I}$ & 0.237 & 0.001 & $<0.00 \mathrm{I}$ \\
\hline
\end{tabular}

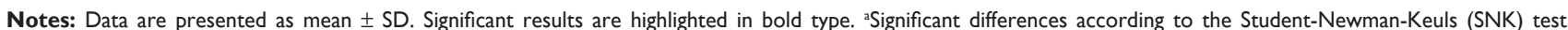
$(p<0.05)$.

Abbreviations: DBAS-16, Dysfunctional Beliefs and Attitudes about Sleep Scale; PSQI, Pittsburgh Sleep Quality Index. 
Table 3 Correlations among dependent and independent variables

\begin{tabular}{|c|c|c|c|c|c|}
\hline Variables & $\begin{array}{l}\text { DBAS-16 } \\
\text { medication }\end{array}$ & $\begin{array}{l}\text { DBAS-16 } \\
\text { expectations }\end{array}$ & $\begin{array}{l}\text { DBAS- } 16 \text { worryl } \\
\text { helplessness }\end{array}$ & $\begin{array}{l}\text { DBAS-16 } \\
\text { consequences }\end{array}$ & $\begin{array}{l}\text { DBAS-16 } \\
\text { total }\end{array}$ \\
\hline DBAS-16 medication & - & & & & \\
\hline DBAS- 16 expectations & $0.154 *$ & - & & & \\
\hline DBAS-16 worry/helplessness & $0.489 *$ & $0.285^{*}$ & - & & \\
\hline DBAS- 16 consequences & $0.319 *$ & $0.373 *$ & $0.56 I^{*}$ & - & \\
\hline DBAS- 16 total & $0.664 *$ & $0.513^{*}$ & $0.867^{*}$ & $0.81 I^{*}$ & - \\
\hline PSQI sleep quality & 0.005 & $-0.069 * *$ & $-0.190 *$ & $-0.109 *$ & $-0.140 *$ \\
\hline PSQI sleep latency & -0.041 & -0.020 & $-0.179 *$ & $-0.102 *$ & $-0.136 *$ \\
\hline PSQI sleep duration & 0.005 & $0.112 *$ & $-0.067 * *$ & -0.033 & -0.020 \\
\hline PSQI sleep efficiency & 0.002 & 0.028 & -0.033 & -0.009 & -0.013 \\
\hline PSQI sleep disturbances & $-0.084^{*}$ & -0.035 & $-0.127^{*}$ & $-0.055^{* *}$ & $-0.110 *$ \\
\hline PSQI sleeping medication & $-0.23 I^{*}$ & -0.041 & $-0.112^{*}$ & -0.016 & $-0.131 *$ \\
\hline PSQI daytime dysfunction & $-0.094^{*}$ & $-0.097^{*}$ & $-0.20 I^{*}$ & $-0.167^{*}$ & $-0.202 *$ \\
\hline PSQI total & $-0.098 *$ & -0.030 & $-0.242 *$ & $-0.136^{*}$ & $-0.197 *$ \\
\hline
\end{tabular}

Note: $* p<0.05$ and $* * p<0.01$.

Abbreviations: DBAS-16, Dysfunctional Beliefs and Attitudes about Sleep Scale; PSQI, Pittsburgh Sleep Quality Index.

examined. Sleep disturbances, as measured by the PSQI total score, were negatively correlated with the DBAS-16 total score. Distorted beliefs about sleep were associated with poor sleep quality. In addition, for PSQI subscales, sleep quality subscale was correlated with DBAS-16 expectations subscale, DBAS-16 worry/helplessness subscale, DBAS-16 consequences subscale, and DBAS-16 total score. Sleep latency was correlated with DBAS-16 worry/ helplessness subscale, DBAS- 16 consequences subscale, and DBAS-16 total score. Sleep duration was only associated with DBAS-16 expectations subscale and DBAS-16 worry/ helplessness subscale. Sleep efficiency was not correlated with any DBAS-16 subscale. Sleep disturbance was correlated with DBAS-16 medication subscale, DBAS-16 worry/ helplessness subscale, DBAS- 16 consequences subscale, and DBAS-16 total score. The use of sleeping medication was correlated with DBAS-16 medication subscale, DBAS-16 worry/helplessness subscale, and DBAS-16 total score. Daytime dysfunction was correlated with all DBAS-16 subscales and DBAS-16 total score.

\section{Behavior factors related to sleep quality}

Figure 1 shows the distribution of participants in relation to different measures they adopted to improve sleep quality. These include self-relaxation, developing good sleep habits, improving the sleep environment, strengthening physical exercise, reading, consulting a doctor, nonaction, and taking sleeping pills. Descriptive data of behavioral factors of the participants are shown in Table 4. Individuals involved in developing good sleep habits, self-relaxation, strengthening physical exercise, and taking sleeping pills, and those who took no action showed significant differences in sleep quality, relative to those who were not involved in these behaviors. Improving the sleep environment, consulting a doctor, and reading did not significantly affect sleep quality.

\section{Discussion}

This study was carried out to assess a subset of dysfunctional beliefs and attitudes about sleep in Chinese college students. This study also focused on assessing whether dysfunctional beliefs about sleep were correlated with insomnia symptoms

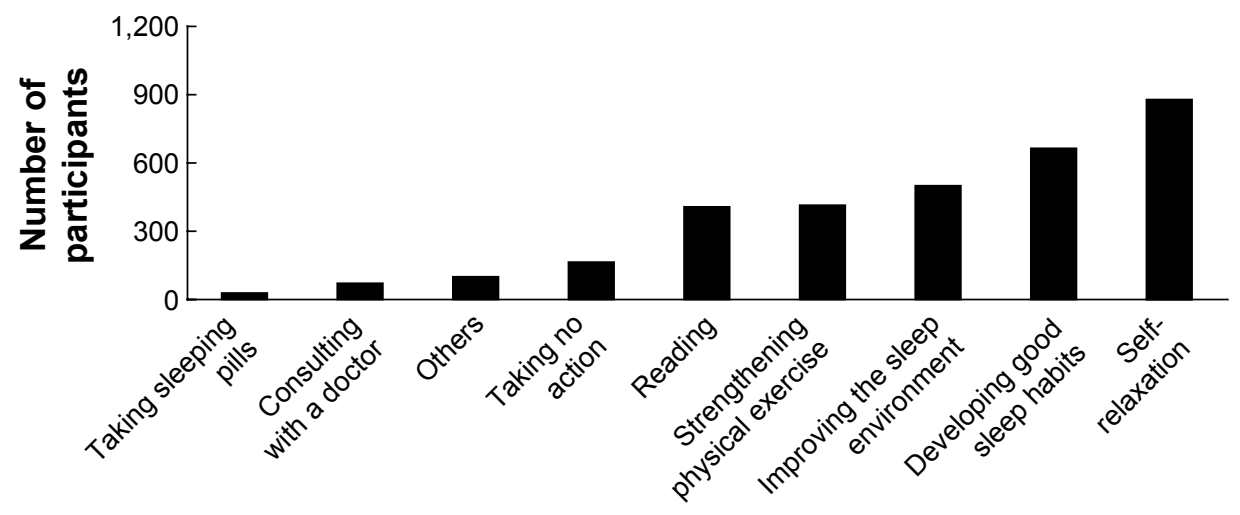

Figure I Distribution of participants with respect to measures for improving sleep quality. 
Table 4 PSQI scores in groups with different behaviors related to sleep

\begin{tabular}{lllll}
\hline Measures & Yes & No & $\boldsymbol{t}$ & $\boldsymbol{p}$-value \\
\hline $\begin{array}{l}\text { Improving the sleep } \\
\text { environment }\end{array}$ & $5.12 \pm 2.366$ & $5.3 \mathrm{I} \pm 2.468$ & $\mathrm{I} .39 \mathrm{I}$ & 0.164 \\
$\begin{array}{l}\text { Developing good sleep } \\
\text { habits }\end{array}$ & $4.92 \pm 2.3 \mathrm{II}$ & $5.55 \pm 2.508$ & $4.8 \mathrm{I} 4$ & $<\mathbf{0 . 0 0 I}$ \\
$\begin{array}{l}\text { Self-relaxation } \\
\text { Consulting a doctor }\end{array}$ & $5.07 \pm 2.278$ & $5.55 \pm 2.678$ & 3.273 & $\mathbf{0 . 0 0 I}$ \\
Strengthening physical & $4.86 \pm 2.449$ & $5.26 \pm 2.430$ & $\mathrm{I} .29 \mathrm{I}$ & 0.197 \\
exercise & $5.40 \pm 2.49 \mathrm{I}$ & 3.923 & $<\mathbf{0 . 0 0 I}$ \\
Taking sleeping pills & $7.03 \pm 3.365$ & $5.19 \pm 2.389$ & 3.074 & $\mathbf{0 . 0 0 4}$ \\
Reading & $5.19 \pm 2.544$ & $5.26 \pm 2.38 \mathrm{I}$ & 0.472 & 0.637 \\
Taking no action & $6.07 \pm 2.678$ & $5.12 \pm 2.374$ & 4.277 & $<\mathbf{0 . 0 0 I}$ \\
Others & $5.32 \pm 2.322$ & $5.23 \pm 2.44 \mathrm{I}$ & 0.342 & 0.733 \\
\hline
\end{tabular}

Notes: Data are mean $\pm S D$. Significant results are highlighted in bold type.

Abbreviation: PSQI, Pittsburgh Sleep Quality Index.

and whether dysfunctional beliefs and attitudes about sleep differed in participants with different behaviors related to sleep quality. The results indicated that individuals with high DBAS-16 scores had low PSQI scores. Thus, beliefs about sleep may play a significantly important role in improving sleep quality. The mean DBAS-16 score of participants was lower than that reported by Crönlein et al. ${ }^{15}$ This indicates that the students' beliefs about sleep need to be improved further. The DBAS-16 total scores did not differ among the different age groups of participants. A previous study has also found no significant changes in the prevalence of severe insomnia with age. ${ }^{37}$ However, the DBAS-16 total score of medical college students was significantly higher than that of nonmedical college students. Thus, medical education may have important implications for correcting erroneous beliefs. A previous study has found that poor sleep quality was quite common in the female population, with $38 \%$ of females suffering from poor sleep. ${ }^{38}$ Similarly, in the present study, female groups reported more distorted perceptions of sleep deficits than male groups. This may be due to the fact that depression occurs more commonly in females than in males. ${ }^{39}$

The results of the present study are consistent with those found in different populations in the previous studies, suggesting that poor sleepers' beliefs about sleep are worse than those of good sleepers. ${ }^{40,41}$ Moreover, poor sleepers and good sleepers differed significantly in three-factor scores of the DBAS-16: consequences of insomnia, worry/helplessness about sleep, and medication. Therefore, these beliefs may make college students with insomnia to experience more anxiety and disturbance in their activities, including their sleep. In addition, the present finding demonstrates a possibility that distorted beliefs about sleep may not only be a predisposing factor for the development of insomnia but also be a potential target for insomnia treatment in this population. Nevertheless, its exact psychological or physiological mechanisms require further studies.

The DBAS-16 scale involves four subscales related to beliefs about sleep. The DBAS-16 expectations of good sleepers in this study were not significantly different from those of poor sleepers, but DBAS-16 medication, DBAS- 16 worry/helplessness, DBAS-16 consequences, and DBAS-16 total scores of good sleepers differed significantly from those of poor sleepers. Therefore, the DBAS-16 scores of good sleepers may differ significantly from those of poor sleepers in general, which implies that negative cognitive activity about sleep may be a risk factor for the recurrence of sleep disorders. The PSQI daytime dysfunction was very strongly associated with the DBAS-16 total score in this study. This indicates that daytime function is mostly affected by presleep cognitive activity and difficulty in sleeping may be closely related to daytime fatigue. Among the DBAS-16 scores, DBAS-16 helplessness had the strongest correlation with the PSQI total score, which implies that helplessness may play a dominant role in the effect of distorted perceptions about sleep on sleep quality. The results further support the small sample study of 400 medical students by Doos et al. ${ }^{42}$ The role of DBAS-16 was similar to that of subjective and objective sleep measures, and it was the most potent indicator of predictors of insomnia recurrence in the literature. Overestimating the extent of perceived sleep deficit for individuals, although in most cases regarded as excessive, may be adaptive for individuals in the early stages of recovery. ${ }^{43}$ The findings in this study suggest that sleep disorders may be recognized early through erroneous beliefs about sleep and that the rate of relapse after detoxification may be reduced by using specially designed cognitive therapy.

Subjects with the behaviors of developing good sleep habits, self-relaxation, and strengthening physical exercise had better sleep quality than those without these behaviors. This indicates that participants with good sleep may benefit from behaviors about sleep such as self-relaxation, developing good sleep habits, and strengthening physical exercise. In addition, individuals with behaviors of taking sleeping pills and those who took no action at all had significantly lower sleep quality when compared to groups without these behaviors. This suggests that the application of a specially designed CBT model for treating sleep problems in this population is worth exploring. It is clear that beliefs and behaviors about sleep are important factors and the failure 
to participate in the treatment of sleep disorders can easily compromise prospects of recovery.

While there is a significant value in these results, there are some limitations. This population has its own specific lifestyle and age range, so these results may not apply to all populations. In terms of the significant correlation between sleep perception and personal sleep quality, the correlation is within small and medium ranges. Factors other than beliefs, such as sleep environment, may have positive or negative effects on good sleep. The significant results were all associated with very small differences between groups. Moreover, a statistical correlation does not mean that there must be a causal relationship. It is not impossible for excessive cognitive activity to be formed due to increased psychological stress after insomnia, although the partial correlation results show that this possibility is unlikely.

\section{Conclusion}

The results of this study indicate that dysfunctional beliefs and attitudes about sleep are closely associated with sleep quality and should be discouraged especially for females and nonmedical college students in Chinese colleges. Students with incorrect beliefs and attitudes are more likely to sleep poorly.

\section{Acknowledgments}

This survey was funded by the Anhui Provincial Natural Science Foundation of China (grant number 1608085MH219). We thank all the study participants for their help in preparing and carrying out the fieldwork.

\section{Author contributions}

HY designed the study and conceived the survey. JZ and HP collected epidemiological data. SD sorted the data. $\mathrm{LJ}$ and $\mathrm{JZ}$ were involved in the fieldwork. LJ conducted the analysis and wrote the first draft of the manuscript. HY evaluated the results and revised the manuscript. All authors approved the final version of the manuscript. All authors contributed toward data analysis, drafting and revising the paper and agree to be accountable for all aspects of the work.

\section{Disclosure}

The authors report no conflicts of interest in this work.

\section{References}

1. Okajima I, Nakajima S, Ochi M, Inoue Y. Reducing dysfunctional beliefs about sleep does not significantly improve insomnia in cognitive behavioral therapy. PLoS One. 2014;9(7):e102565.
2. Roth T, Roehrs T. Insomnia: epidemiology, characteristics, and consequences. Clin Cornerstone. 2003;5(3):5-15.

3. Crum RM, Storr CL, Chan YF, Ford DE. Sleep disturbance and risk for alcohol-related problems. Am J Psychiatry. 2004;161(7):1197-1203.

4. Jung Y, Junna MR, Mandrekar JN, Morgenthaler TI. The national healthy sleep awareness project sleep health surveillance questionnaire as an obstructive sleep apnea surveillance tool. J Clin Sleep Med. 2017;13(9):1067-1074.

5. Mcknight-Eily LR, Liu Y, Wheaton AG, et al; Centers for Disease Control and Prevention (CDC). Unhealthy sleep-related behaviors 12 states, 2009. MMWR Morb Mortal Wkly Rep. 2011;60(8):233-238.

6. Nielsen LS, Danielsen KV, Sørensen TI. Short sleep duration as a possible cause of obesity: critical analysis of the epidemiological evidence. Obes Rev. 2011;12(2):78-92.

7. Cappuccio FP, Cooper D, D’Elia L, Strazzullo P, Miller MA. Sleep duration predicts cardiovascular outcomes: a systematic review and meta-analysis of prospective studies. Eur Heart J. 2011;32(12): 1484-1492.

8. Nakata A. Work hours, sleep sufficiency, and prevalence of depression among full-time employees: a community-based cross-sectional study. J Clin Psychiatry. 2011;72(5):605-614.

9. Harvey AG. A cognitive model of insomnia. Behav Res Ther. 2002; 40(8):869-893.

10. Arnedt JT, Conroy DA, Armitage R, Brower KJ. Cognitive-behavioral therapy for insomnia in alcohol dependent patients: a randomized controlled pilot trial. Behav Res Ther. 2011;49(4):227-233.

11. Carney CE, Harris AL, Friedman J, Segal ZV. Residual sleep beliefs and sleep disturbance following cognitive behavioral therapy for major depression. Depress Anxiety. 2011;28(6):464-470.

12. Eidelman P, Talbot L, Ivers H, Bélanger L, Morin CM, Harvey AG. Change in dysfunctional beliefs about sleep in behavior therapy, $\operatorname{cog}$ nitive therapy, and cognitive-behavioral therapy for insomnia. Behav Ther. 2016;47(1):102-115.

13. Sánchez-Ortuño MM, Edinger JD. A penny for your thoughts: patterns of sleep-related beliefs, insomnia symptoms and treatment outcome. Behav Res Ther. 2010;48(2):125-133.

14. Kuo MF, Nitsche MA. Effects of transcranial electrical stimulation on cognition. Clin EEG Neurosci. 2012;43(3):192-199.

15. Crönlein T, Wagner S, Langguth B, Geisler P, Eichhammer P, Wetter TC. Are dysfunctional attitudes and beliefs about sleep unique to primary insomnia? Sleep Med. 2014;15(12):1463-1467.

16. Gregory AM, Cox J, Crawford MR, Holland J, Harvey AG, Team S. Dysfunctional beliefs and attitudes about sleep in children. J Sleep Res. 2009;18(4):422-426.

17. Carney CE, Edinger JD, Manber R, Garson C, Segal ZV. Beliefs about sleep in disorders characterized by sleep and mood disturbance. J Psychosom Res. 2007;62(2):179-188.

18. Owens JA, Spirito A, Mcguinn M, Nobile C. Sleep habits and sleep disturbance in elementary school-aged children.J Dev Behav Pediatr. 2000; 21(1):27-36

19. Okajima I, Nakajima S, Ochi M, Inoue Y. Association among changes in sleep-related beliefs, sleep reactivity, and improvement of insomnia following cognitive behavioral therapy. Sleep Med. 2016;29:96-97.

20. Mi PDR, Mendo LS, León DBB, Felipe CE. Mobile abuse in University students and profiles of victimization and aggression. Adicciones. 2017; 29(4):245-255.

21. Tokiya M, Kaneita Y, Itani O, Jike M, Ohida T. Predictors of insomnia onset in adolescents in Japan. Sleep Med. 2017;38:37-43.

22. Arora T, Broglia E, Thomas GN, Taheri S. Associations between specific technologies and adolescent sleep quantity, sleep quality, and parasomnias. Sleep Med. 2014;15(2):240-247.

23. Casement MD, Keenan KE, Hipwell AE, Guyer AE, Forbes EE. Neural reward processing mediates the relationship between insomnia symptoms and depression in adolescence. Sleep. 2015;39(2):297-317.

24. Roberts RE, Roberts CR, Hao TD. Chronic insomnia and its negative consequences for health and functioning of adolescents: a 12-month prospective study. J Adolesc Health. 2008;42(3):294-302. 
25. Iglowstein I, Jenni OG, Molinari L, Largo RH. Sleep duration from infancy to adolescence: reference values and generational trends. Pediatrics. 2003;111(2):302-307.

26. Kloss JD, Nash CO, Walsh CM, Culnan E, Horsey S, Sextonradek K. A "sleep 101" program for college students improves sleep hygiene knowledge and reduces maladaptive beliefs about sleep. Behav Med. 2016;42(1):48-56.

27. Morin CM, Stone J, Trinkle D, Mercer J, Remsberg S. Dysfunctional beliefs and attitudes about sleep among older adults with and without insomnia complaints. Psychol Aging. 1993;8(3):463-467.

28. Morin CM, Vallières A, Ivers H. Dysfunctional beliefs and attitudes about sleep (DBAS): validation of a brief version (DBAS-16). Sleep. 2007;30(11):1547-1554.

29. Carney CE, Edinger JD, Morin CM, et al. Examining maladaptive beliefs about sleep across insomnia patient groups. J Psychosom Res. 2010; 68(1):57-65.

30. Lancee J, Eisma MC, Straten AV, Kamphuis JH. Sleep-related safety behaviors and dysfunctional beliefs mediate the efficacy of online CBT for insomnia: a randomized controlled trial. Cogn Behav Ther. 2015; 44(5):406-422.

31. Chung KF, Ho FY, Yeung WF. Psychometric comparison of the full and abbreviated versions of the dysfunctional beliefs and attitudes about sleep scale. J Clin Sleep Med. 2016;12(6):821-828.

32. Afolalu EF, Moore C, Ramlee F, Goodchild CE, Tang NK. Development of the Pain-Related Beliefs and Attitudes about Sleep (PBAS) scale for the assessment and treatment of insomnia comorbid with chronic pain. J Clin Sleep Med. 2016;12(9):1269-1277.

33. Fu SX, Ou HX, Lu SH. Reliability and validity of the brief version of dysfunctional beliefs and attitudes about sleep. Chin J Behav Med Brain Sci. 2014;23(4):369-371.

34. Buysse DJ, Rd RC, Monk TH, Berman SR, Kupfer DJ. The Pittsburgh sleep quality index: a new instrument for psychiatric practice and research. Psychiatry Res. 1989;28(2):193-213.
35. Zheng B, Li M, Wang KL, Lv J. [Analysis of the reliability and validity of the Chinese version of Pittsburgh sleep quality index among medical college students]. Beijing Da Xue Xue Bao. 2016;48(3):424-428. Chinese.

36. Dong-Gui QI, Liu R, Xiao-Xi WU. Investigation on sleeping quality of university students and its influential factors. Mod Prev Med. 2007; 34:875-877.

37. Hajak G; SINE Study Group. Study of Insomnia in Europe. Epidemiology of severe insomnia and its consequences in Germany. Eur Arch Psychiatry Clin Neurosci. 2001;251(2):49-56.

38. Kravitz HM, Ganz PA, Bromberger J, Powell LH, Suttontyrrell K, Meyer PM. Sleep difficulty in women at midlife: a community survey of sleep and the menopausal transition. Menopause. 2003;10(1):19-28.

39. Blumel JE, Chedraui P, Baron G, et al; Collaborative Group for Research of the Climacteric in Latin America (REDLINC). A large multinational study of vasomotor symptom prevalence, duration, and impact on quality of life in middle-aged women. Menopause. 2011;18(7):778-785.

40. Yang C-M, Chou CP-W, Hsiao F-C. The association of dysfunctional beliefs about sleep with vulnerability to stress-related sleep disturbance in young adults. Behav Sleep Med. 2011;9(2):86-91.

41. Aitken D, Naismith SL, Terpening Z, Lewis SJG. Dysfunctional sleep beliefs in Parkinson's disease: relationships with subjective and objective sleep. J Clin Neurosci. 2014;21(8):1359-1363.

42. Doos AVH, Gharraee B, Farid AA, Bandi MG. Prediction of insomnia severity based on cognitive, metacognitive, and emotional variables in college students. Explore (NY). 2014;10(4):233-240.

43. Smith N, Hill R, Marshall J, Keaney F, Wanigaratne S. Sleep related beliefs and their association with alcohol relapse following residential alcohol detoxification treatment. Behav Cogn Psychother. 2014; 42(5):593-604.
Neuropsychiatric Disease and Treatment

\section{Publish your work in this journal}

Neuropsychiatric Disease and Treatment is an international, peerreviewed journal of clinical therapeutics and pharmacology focusing on concise rapid reporting of clinical or pre-clinical studies on a range of neuropsychiatric and neurological disorders. This journal is indexed on PubMed Central, the 'PsycINFO' database and CAS,

\section{Dovepress}

and is the official journal of The International Neuropsychiatric Association (INA). The manuscript management system is completely online and includes a very quick and fair peer-review system, which is all easy to use. Visit http://www.dovepress.com/testimonials.php to read real quotes from published authors. 